
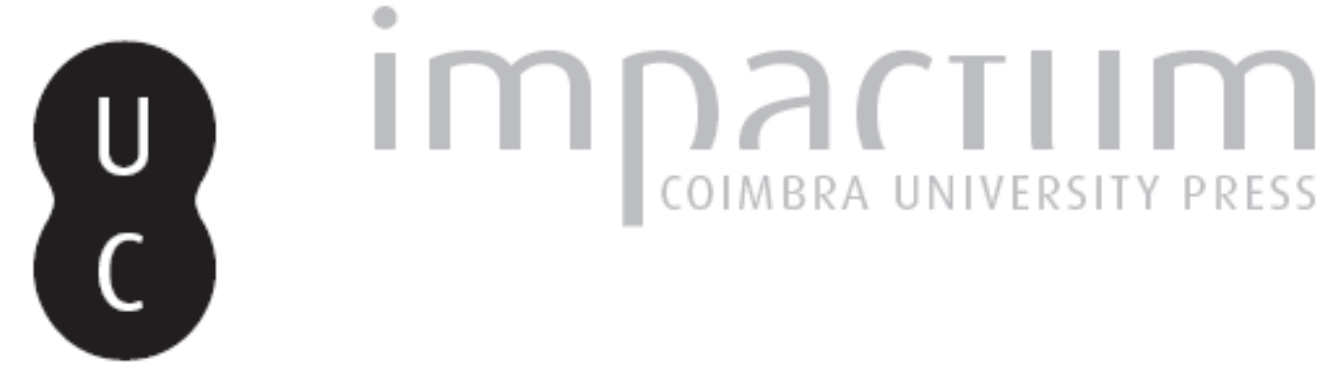

Indústria e inovação em Portugal: análise do Community Innovation Survey 2008

Autor(es): $\quad$ Gama, Rui; Fernandes, Ricardo

Publicado por: $\begin{aligned} & \text { Faculdade de Letras da Universidade de Coimbra, Departamento de } \\ & \text { Geografia }\end{aligned}$

URL

persistente:

URI:http://hdl.handle.net/10316.2/30214

DOI:

DOI:http://dx.doi.org/10.14195/0871-1623_31_14

Accessed : $\quad$ 26-Apr-2023 10:52:46

A navegação consulta e descarregamento dos títulos inseridos nas Bibliotecas Digitais UC Digitalis, UC Pombalina e UC Impactum, pressupõem a aceitação plena e sem reservas dos Termos e Condições de Uso destas Bibliotecas Digitais, disponíveis em https://digitalis.uc.pt/pt-pt/termos.

Conforme exposto nos referidos Termos e Condições de Uso, o descarregamento de títulos de acesso restrito requer uma licença válida de autorização devendo o utilizador aceder ao(s) documento(s) a partir de um endereço de IP da instituição detentora da supramencionada licença.

Ao utilizador é apenas permitido o descarregamento para uso pessoal, pelo que o emprego do(s) título(s) descarregado(s) para outro fim, designadamente comercial, carece de autorização do respetivo autor ou editor da obra.

Na medida em que todas as obras da UC Digitalis se encontram protegidas pelo Código do Direito de Autor e Direitos Conexos e demais legislação aplicável, toda a cópia, parcial ou total, deste documento, nos casos em que é legalmente admitida, deverá conter ou fazer-se acompanhar por este aviso.

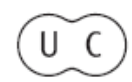




\section{Indústria e inovação em Portugal: análise do Community Innovation Survey 2008}

\section{Rui Gama}

Departamento de Geografia e Centro de Estudos de Geografia e Ordenamento do Território (CEGOT). Faculdade de Letras da Universidade de Coimbra. rgama@fl.uc.pt

\section{Ricardo Fernandes}

Departamento de Geografia e Centro de Estudos de Geografia e Ordenamento do Território (CEGOT). Faculdade de Letras da Universidade de Coimbra. Bolseiro de Doutoramento da Fundação para a Ciência e Tecnologia (FCT) - SFRH/BD/44371/2008.

r.fernandes@fl.uc.pt

\section{Resumo:}

Num contexto marcado, quer por rápidas mudanças tecnológicas e sociais quer por uma crescente integração e interdependência das atividades económicas à escala global, a inovação é considerada como o principal motor do desenvolvimento socioeconómico. O Community Innovation Survey 2008 assume-se como uma fonte para que se possa avaliar as atividades e processos de inovação em Portugal, ao nível do produto, do processo e da inovação organizacional e de marketing, bem como dos seus condicionantes, resultados e fragilidades/potencialidades. Tendo por base a análise do contexto socioeconómico português, torna-se essencial perceber como é que a inovação tem sido incorporada neste início de século nas estratégias das empresas e quais os reflexos observados na mudança de comportamentos e padrões territoriais.

Palavras-chave: Indústria. Inovação. CIS 2008. Desenvolvimento regional. Portugal.

\section{Résumé:}

L'industrie et l'innovation au Portugal: analyse de l'enquête communautaire sur l'innovation 2008

Dans un contexte marqué par des changements technologiques et sociaux et une intégration croissante et l'interdépendance des activités économiques à l'échelle mondiale, l'innovation est considérée comme le principal moteur de développement économique. L'Enquête communautaire sur l'innovation 2008 est considérée comme une source qui permet une évaluation des activités et des processus d'innovation au Portugal, en termes de produit ou d'un procédé, de commercialisation ou organisationnelle, tout en permettant d'identifier les contraintes, les résultats, les faiblesses et les forces. Basé sur l'analyse de contexte socio-économique, l'objectif de la recherche vise à comprendre comment l'innovation a été intégrée dans les stratégies des entreprises au Portugal, et d'évaluer les changements dans les comportements des entrepreneurs et des dynamiques territoriales.

Mots-clés: Industrie. Innovation. CIS 2008. Développement régional. Portugal.

\section{Abstract:}

Industry and innovation in Portugal: analysis of the Community Innovation Survey 2008

In a context characterized by, both, a fast technological and social changes and by a growing integration and interdependence of economic activities on a global scale, innovation is considered as the main driver for economic development. The Community Innovation Survey 2008 positions itself as a source where one can evaluate the activities and the innovation process in Portugal, in terms of product, process and organizational innovation and marketing, as well as their determinants, fragilities/capabilities. Based upon the analysis of the Portuguese socio-economic context, it is essential to understand how, in this new century, innovation is part of the companies strategies and how it is reflected on behavioral change and territorial patterns.

Keywords: Industry. Innovation. CIS 2008. Regional development. Portugal. 


\section{Introdução}

A inovação assume-se no atual contexto de competição à escala global como o elemento central de qualquer estratégia pensada e definida pelas empresas. Com efeito, a crescente integração e interdependência económica das empresas promove uma competição, em que a valorização simultânea das relações nos territórios locais e a presença em redes globais de produção, são fatores fundamentais para o sucesso de qualquer estratégia empresarial/territorial.

Neste sentido, quer a mobilização de recursos humanos e materiais diversificados quer as vantagens que decorrem das atividades desenvolvidas pelas organizações e instituições intervenientes no processo de inovação, assumem-se como elementos decisivos para o sucesso de empresas e territórios.

A aquisição de competências dinâmicas, ao promoveram e facilitarem a competitividade das empresas e dos territórios, deve ser, neste contexto, o quadro de referência para a definição da estratégia individual de cada empresa e para as políticas públicas de suporte à inovação.

Tendo por base este pano de fundo, utiliza-se o Community Innovation Survey 2008 como uma fonte para que se possa avaliar as atividades e processos de inovação em Portugal, ao nível do produto, do processo e da inovação organizacional e de marketing, bem como dos seus condicionantes, resultados e fragilidades/ potencialidades. A investigação considera o contexto socioeconómico dos territórios, valorizando as caraterísticas estruturais e os aspetos relativos à dinâmica empresarial, tentando depois perceber de que forma é que a inovação tem sido incorporada nas estratégias das empresas e quais os reflexos registados na mudança dos comportamentos e padrões territoriais.

\section{Dinâmica empresarial, inovação e território}

A análise da dinâmica empresarial que os territórios evidenciam, quantificada através das empresas e dos recursos humanos, deve considerar também as dimensões da riqueza criada (valor acrescentado bruto), investimentos em inovação e quadro institucional de suporte à atividade industrial.

Mesmo tendo em atenção que algumas investigações referem que o emprego industrial e as empresas se encontram num ligeiro processo de dispersão e desconcentração (GAMA, 2004), verifica-se na atualidade que estas variáveis acabam por ter uma tradução territorial que evidencia um marcado caráter de aglomeração, demarcando espaços de forte apetência industrial e marginalizando outros de fraca vocação industrial. Esta configuração territorial traduz trajetórias de desenvolvimento que vincam as especializações produtivas, a acumulação de competências e o aproveitamento dos apoios da política pública de inovação no quadro da União Europeia. Um primeiro elemento de análise que permite evidenciar as dinâmicas territoriais em Portugal e as caraterísticas económicas e sociais dos espaços industriais, decorre da avaliação do índice de industrialização ${ }^{1}$ (Figura 1). Considerando o valor acrescentado bruto por setor industrial (CAE, Rev. 3 - C), destaca-se o padrão litoralizado da criação de riqueza e as aglomerações industriais das duas Áreas Metropolitanas, Norte e Sul, e o Centro Litoral. Esta configuração traduz quer as trajetórias de industrialização portuguesas, quer uma marcada especialização setorial (casos de Palmela, Sines, Figueira da Foz, Mangualde e Vila Velha de Rodão). No caso do território Norte referem-se com índices de industrialização superiores a 1 ou mesmo a 2, os concelhos das sub-regiões do Ave (Guimarães, Santo Tirso, Trofa e Vila Nova de Famalicão), Grande Porto (Maia, Matosinhos e Vila do Conde), Tâmega (Felgueiras e Paços de Ferreira) e Entre Douro e Vouga (Oliveira de Azeméis, Santa Maria da Feira, São João da Madeira e Vale de Cambra). No Centro Litoral destacam-se os concelhos do Baixo Vouga (Águeda, Albergaria-a-Velha e Aveiro com valores superiores a 2), Baixo Mondego (Figueira da Foz e Cantanhede), Pinhal Litoral (BataIha, Leiria, Marinha Grande e Porto de Mós), Dão-Lafões (Oliveira de Frades, Mangualde e Tondela), Oeste (Alcobaça e Alenquer) e Médio Tejo (Alcanena e Constância). Por outro lado, este padrão de industrialização é marcado por uma estrutura produtiva com caraterísticas de maior diversificação nos territórios de forte presença industrial e de especialização (calculada com o valor acrescentado bruto) nos territórios como menores níveis de presença industrial (Figura 2).

Uma outra dimensão analítica sublinha que os territórios mais industrializados perderam emprego no setor industrial na primeira década do atual século (Quadro 1). Com efeito, de 1998 a 2008, as sub-regiões do Grande Porto, Ave e Entre Douro e Vouga registaram

10 Índice de Industrialização tem por base do Índice de Alexandersson, relacionando as unidades espaciais com o valor no total das unidades, em duas dimensões diferentes $\left(X_{i j} / X_{i j}\right) /\left(X_{i} / X\right)$. O $X_{i j}$ e o $X_{i}$ referemse aos valores do valor acrescentado bruto numa determinada unidade espacial e na unidade administrativa superior (Continente); por outro lado $X_{i}$ e o $X$, correspondem à população residente. Os valores superiores a 1 indicam que, para uma determinada unidade, existe uma maior importância do valor acrescentado bruto na indústria comparativamente à correspondente relação populacional. 


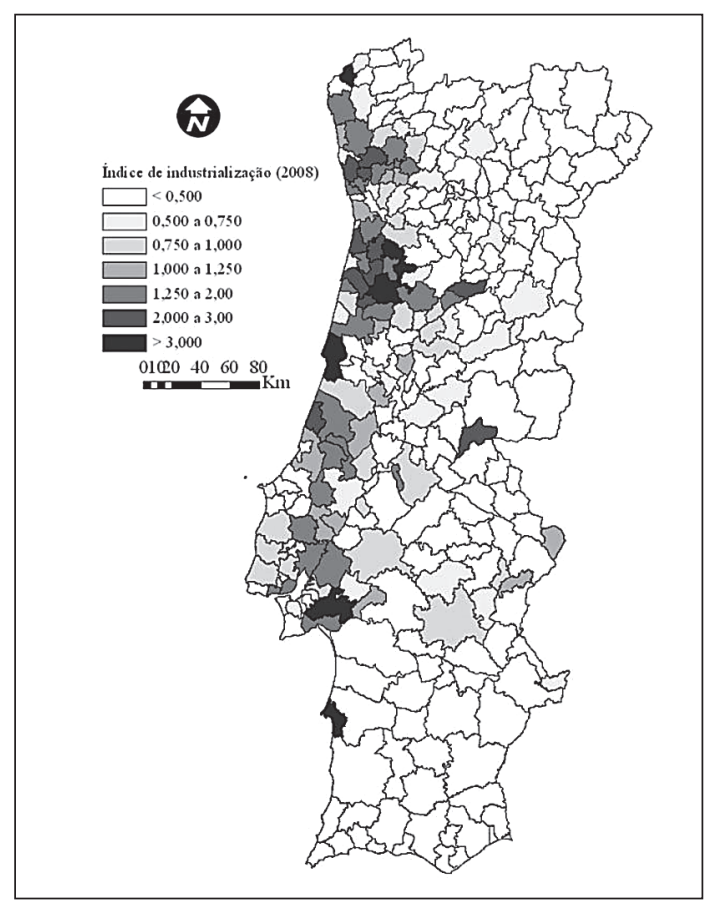

Figura 1

Índice de industrialização (2008)

Fonte: INE (2010), Anuários Estatísticos (Norte, Centro, Lisboa, Alentejo, Algarve), INE, Lisboa e INE (2012), Censos 2011, Resultados Provisórios, INE, Lisboa (http/www.ine.pt).

uma variação de emprego industrial de $-28,3 \%,-12,4 \%$ e $-8,8 \%$, respetivamente. No caso do Tâmega registou-se um reforço de 7,5\%. Também nas sub-regiões do Centro Litoral se verificou uma perda de emprego industrial, mas com menor expressão. Efetivamente, Baixo Vouga e Pinhal Litoral registam perdas de 3,2\% e 3,5\%, respetivamente. No caso do Dão-Lafões verificou-se um acréscimo de $27,3 \%$. A Grande Lisboa e Península de Setúbal perderam respetivamente $28,0 \%$ e $21,3 \%$ do emprego na indústria. O Alentejo Central teve um acréscimo de $53,7 \%$. Esta evolução deve ser entendida num quadro de modernização do tecido produtivo e do aparecimento de novas dinâmicas industriais, tal como os dados do investimento realizado no âmbito do QREN parecem indicar.

Considerando o investimento elegível financiado no quadro do Programa Operacional Fatores de Competitividade do QREN, são as sub-regiões indicadas as que apresentam maior peso considerando o valor total disponibilizado até 28 de março de 2012 (4 550233160 euros num total de 2464 projetos). Mais especificamente, as sub-regiões do Centro Litoral apresentam percentagens de investimento de $11,4 \%$ (Baixo Vouga) e 9,7\%
(Baixo Mondego), contra 9,6\% do Ave. Grande Lisboa e Península de Setúbal representam respetivamente 0,6\% e $0,3 \%$ do investimento total. Neste contexto, a subregião do Médio Tejo é a que realiza o maior investimento $(20,6 \%)$. Estes dados parecem confirmar a importância do quadro de partida e da capacidade industrial instalada para o aproveitamento dos apoios da política industrial, ao mesmo tempo que se detetam novas dinâmicas. Na leitura dos dados do QREN deve ter-se em atenção que nos territórios do Norte e Centro Litoral o investimento realizado na indústria representa mais de $80 \%$ do investimento realizado. No caso de Lisboa, a indústria representa na Grande Lisboa apenas 18,8\% e na Península de Setúbal 55,9\%.

Por outro lado, são também estes territórios mais industrializados que apresentam os maiores valores de produtividade (valor acrescentando bruto por traba(hador). Os dados do investimento também mostram a concentração em projetos âncora no Alentejo Litoral (Sines) e no Médio Tejo (Abrantes).

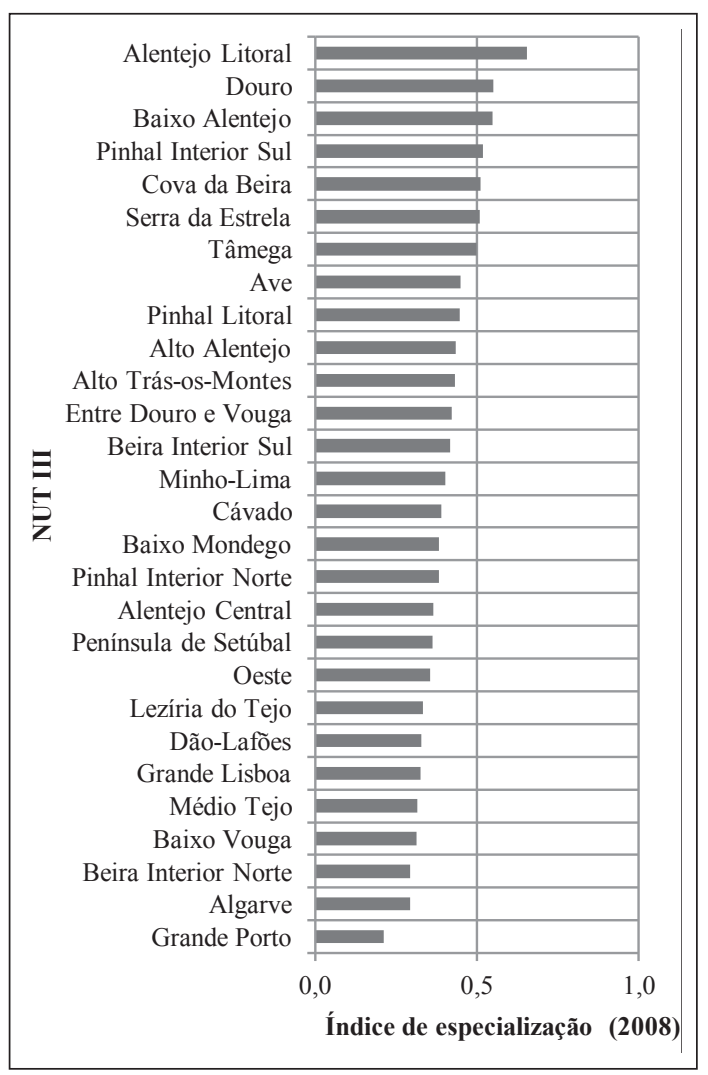

Figura 2

Índice de especialização (2008)

Fonte: INE (2010), Anuários Estatísticos (Norte, Centro, Lisboa, Alentejo, Algarve), INE, Lisboa e INE (2012), Censos 2011, Resultados Provisórios, INE, Lisboa (http/www.ine.pt). 
O processo de industrialização em Portugal apresenta assim um reforço do padrão marcadamente litoral, com caraterísticas que evidenciam o peso da trajetória seguida, que tem sido reforçada com o apoio dos instrumentos da política industrial.

\section{Empresas e inovação: CIS 2008 - Inquérito Comunitário à Inovação 2008}

\subsection{Enquadramento do CIS 2008}

No sentido da criação de condições para que as empresas e os territórios sejam competitivos à escala global, inovar continuamente assume-se como a principal preocupação de empresários e agentes institucionais ao definirem estratégias e políticas industriais de base territorial.

O desenvolvimento científico e a inovação são vetores centrais para a criação de condições que fomentem a produtividade das empresas, alterando a organização produtiva e valorizando os recursos humanos, ao potenciar as competências existentes e criando condições para antecipar o futuro, num contexto de competição que deve considerar sempre diferentes escalas geográficas (da local à global).

Será a partir do CIS 2008 - Inquérito Comunitário à Inovação 2008 (Community Innovation Survey 2008) que se irá analisar o processo de inovação e o comportamento dos diferentes agentes do sistema de conhecimento e inovação em Portugal. Este inquérito é o principal instrumento de recolha de informação estatística sobre as caraterísticas das atividades de inovação das empresas europeias, assentando nos princípios concetuais do Manual de Oslo (OCDE, 2005), que determina as linhas de orientação para a recolha, armazenamento, tratamento e interpretação dos dados/informação acerca da inovação, e das recomendações metodológicas do Eurostat, visando a produção de estatísticas de inovação harmonizadas entre os estados-membros.

Quadro I

Indicadores de industrialização, por sub-região

\begin{tabular}{|c|c|c|c|c|c|c|c|}
\hline NUTSIII & \begin{tabular}{|c|} 
Var. pessoal \\
$1998-2008(\%)$
\end{tabular} & $\begin{array}{c}\text { Índice de } \\
\text { industrialização } \\
2008\end{array}$ & $\begin{array}{c}\text { Índice de } \\
\text { especialização } \\
2008\end{array}$ & $\begin{array}{c}\text { Produtividade } \\
\text { (1000 euros) }\end{array}$ & Investimento (\%) & $\begin{array}{c}\text { Inv. Indústria em } \\
\text { relação ao Total } \\
\text { (\%) }\end{array}$ & $\begin{array}{l}\text { Inv. por projeto } \\
\text { Indústria (euros) }\end{array}$ \\
\hline Minho-Lima & 21,3 & 0,817 & 0,403 & 20,8 & 1,8 & 69,4 & 1465932,00 \\
\hline Cávado & $-1,8$ & 0,993 & 0,390 & 16,3 & 2,4 & 64,5 & 649237,09 \\
\hline Ave & $-12,4$ & 1,886 & 0,450 & 17,7 & 9,6 & 90,7 & 1514582,05 \\
\hline Grande Porto & $-28,3$ & 1,053 & 0,212 & 25,8 & 6,0 & 42,5 & 856427,73 \\
\hline Tâmega & 7,5 & 0,830 & 0,499 & 12,3 & 4,4 & 84,0 & 1079875,71 \\
\hline Entre Douro e Vouga & $-8,8$ & 2,392 & 0,422 & 21,1 & 4,5 & 89,3 & 865837,59 \\
\hline Douro & 35,0 & 0,233 & 0,549 & 18,3 & 0,3 & 23,0 & 415935,76 \\
\hline Alto Trás-os-Montes & 30,5 & 0,250 & 0,431 & 20,1 & 0,6 & 50,6 & 815740,14 \\
\hline Baixo Vouga & $-3,2$ & 2,057 & 0,313 & 26,7 & 11,4 & 89,9 & 1868697,63 \\
\hline Baixo Mondego & $-6,6$ & 0,986 & 0,383 & 36,7 & 9,7 & 83,5 & 5340300,10 \\
\hline Pinhal Litoral & $-3,5$ & 1,493 & 0,446 & 23,9 & 3,8 & 80,7 & 781900,48 \\
\hline Pinhal Interior Norte & $-4,2$ & 0,683 & 0,382 & 17,1 & 1,1 & 77,0 & 1722596,69 \\
\hline Dão-Lafões & 27,3 & 0,936 & 0,329 & 25,4 & 2,6 & 60,0 & 1917811,16 \\
\hline Pinhal Interior Sul & 2,3 & 0,492 & 0,520 & 16,0 & 0,5 & 92,9 & 2742226,75 \\
\hline Serra da Estrela & $-27,0$ & 0,314 & 0,509 & 10,6 & 0,0 & 7,6 & 420186,50 \\
\hline Beira Interior Norte & $-11,1$ & 0,342 & 0,294 & 16,0 & 0,3 & 43,1 & 968286,83 \\
\hline Beira Interior Sul & $-20,7$ & 0,466 & 0,416 & 18,5 & 1,1 & 83,7 & 3275375,47 \\
\hline Cova da Beira & $-38,2$ & 0,617 & 0,512 & 15,3 & 0,0 & 5,2 & 166061,30 \\
\hline Oeste & $-17,9$ & 0,750 & 0,356 & 20,2 & 1,6 & 44,8 & 754443,45 \\
\hline Médio Tejo & $-20,0$ & 0,768 & 0,316 & 21,4 & 20,6 & 97,6 & 11584544,84 \\
\hline Grande Lisboa & $-28,0$ & 1,099 & 0,326 & 43,8 & 0,6 & 18,8 & 845740,83 \\
\hline Península de Setúbal & $-21,3$ & 0,835 & 0,362 & 38,0 & 0,3 & 55,9 & 1175077,00 \\
\hline Alentejo Litoral & 15,1 & 0,959 & 0,654 & 56,1 & 8,0 & 82,2 & 51851617,29 \\
\hline Alto Alentejo & $-19,9$ & 0,290 & 0,434 & 15,4 & 1,1 & 47,2 & 1844595,04 \\
\hline Alentejo Central & 53,7 & 0,665 & 0,364 & 22,4 & 4,5 & 59,2 & 3973957,45 \\
\hline Baixo Alentejo & 97,8 & 0,166 & 0,548 & 14,8 & 0,8 & 15,5 & 3031189,75 \\
\hline Lezíria do Tejo & 3,5 & 0,887 & 0,333 & 25,5 & 2,1 & 73,3 & 1225468,97 \\
\hline Algarve & 22,2 & 0,136 & 0,294 & 13,6 & 0,2 & 6,8 & 482922,94 \\
\hline Continente & $-12,1$ & 1 & & 24,6 & 100,0 & 71,0 & 1846685,54 \\
\hline
\end{tabular}

Fonte: INE (1999), Anuários Estatísticos (Norte, Centro, Lisboa, Alentejo, Algarve), INE, Lisboa e INE (2010), Anuários Estatísticos (Norte, Centro, Lisboa, Alentejo, Algarve), INE, Lisboa. 
Este inquérito foi distribuído em Portugal no período entre 21 de maio de 2009 e 12 de Abril de 2010, correspondendo à sétima operação estatística de recolha de dados comparáveis no quadro europeu. No final do período de recolha de dados foram consideradas como válidas 6593 respostas, de entre as 7952 empresas da amostra corrigida (selecionadas de forma aleatória tendo por base o Ficheiro Geral de Unidades Estatísticas do Instituto Nacional de Estatística), traduzindo uma taxa de resposta de $83 \%$ e um universo de 21567 empresas dos ramos da indústria, construção e serviços (GPEARI/ MCTES, 2010: 7-8).

Da panóplia de variáveis que podem ser extraídas do CIS 2008, foram consideradas apenas algumas para a presente análise, com o objetivo de se caraterizar o processo de inovação e o comportamento dos diferentes agentes no território português. Desta forma, procedeu-se, em primeiro lugar, a uma caraterização económica das empresas com inovação tecnológica e não tecnológica, seguindo-se uma análise mais detalhada à inovação tecnológica e não tecnológica na indústria transformadora (CAE, Rev. 3 - C). Esta análise considerou a dupla dimensão setorial e territorial (NUT II). O facto de não existir uma desagregação espacial mais fina limita a análise territorial. Por outro lado, a análise e interpretação dos dados, quer considerando a dimensão das empresas quer para o nível NUTS II, tem como referencial a totalidade dos setores de atividade e não apenas a indústria transformadora. Também são apenas consideradas empresas com pelo menos 10 trabalhadores. Nos quadros o total da indústria engloba a indústria extrativa (Divisão 05, CAE - Rev. 3), indústria transformadora (10 a 33), eletricidade, gás, vapor, água quente e fria e ar frio (35) e captação, tratamento e distribuição de água; saneamento, gestão de resíduos e despoluição (36 a 39).

\subsection{Dinâmicas de inovação, empresas e território}

A caraterização económica e social das empresas que responderam ao Inquérito Comunitário à Inovação 2008 indica, desde logo, o aprofundamento nas décadas mais recentes do processo de terciarização da economia portuguesa, já que o setor dos serviços é responsável por quase $2 / 3$ do volume de negócios realizado pelas empresas. Acresce que o setor industrial (Divisão 05 a 39) é o que apresenta o maior número de empresas na população alvo (61\%), estando o emprego igualmente repartido entre a indústria e os serviços $(52 \%$ e $48 \%$, respetivamente do total de pessoas) (Quadro II). Por outro lado, as caraterísticas do processo de industrialização recente e a alteração estrutural da economia portuguesa estão patentes no facto de a indústria transformadora representar $58 \%$ das empresas e $46 \%$ do pessoal ao serviço, mas apenas $27 \%$ do volume de negócios.

A caraterização económica e social mostra que o tecido empresarial é dominado por pequenas empresas (10 a 49 empregados), sendo que as grandes empresas (250 ou mais empregados) são responsáveis por cerca de metade do emprego (45\%) e quase $2 / 3$ do volume de negócios (56\%) (Quadro III).

A consideração da variável localização indica que a região Norte representando $45 \%$ das empresas e $37 \%$ dos empregados, realiza apenas $22 \%$ do volume de negócios (Quadro IV). A região de Lisboa como menor número de empresas (24\%) é responsável por $62 \%$ do

Quadro II

Caraterização económica e social das empresas, por ramo de atividade

\begin{tabular}{|c|c|c|c|c|c|c|c|}
\hline \multicolumn{2}{|c|}{ Atividades Económicas (CAE, Rev. 3) } & \multicolumn{2}{|c|}{$\begin{array}{l}\text { Total de empresas na } \\
\text { população alvo }\end{array}$} & \multicolumn{2}{|c|}{ Volume de Negócios } & \multicolumn{2}{|c|}{ Pessoal ao serviço } \\
\hline & & N. ${ }^{\circ}$ & $\%$ & Milhões de euros & $\%$ & N. ${ }^{\circ}$ & $\%$ \\
\hline 05 a 39 & Total Indústria & 13215 & 61 & 97367 & 40 & 649500 & 52 \\
\hline 46 a 86 & Total Serviços & 8352 & 39 & 144235 & 60 & 593319 & 48 \\
\hline \multicolumn{2}{|r|}{ Total Nacional } & 21567 & 100 & 241602 & 100 & 1242819 & 100 \\
\hline 10 a 33 & Indústria Transformadora & 12570 & 58 & 65558 & 27 & 566671 & 46 \\
\hline
\end{tabular}

Fonte: http://www.estatisticas.gpeari.mctes.pt

Quadro III

Caraterização económica e social das empresas, por dimensão (\%)

\begin{tabular}{|c|c|c|c|c|c|c|}
\hline \multirow{2}{*}{$\begin{array}{c}\text { Dimensão }\left(n^{\circ} \text { de }\right. \\
\text { empregados) }\end{array}$} & \multicolumn{2}{|c|}{ Total de empresas na população alvo } & \multicolumn{2}{|c|}{ Volume de Negócios } & \multicolumn{2}{|c|}{ Pessoal ao serviço } \\
\cline { 2 - 7 } & $\mathbf{N .}^{\circ}$ & $\%$ & Milhões de euros & $\%$ & N. ${ }^{\circ}$ & $\%$ \\
\hline $10-49$ & 17501 & 81 & 46630 & 19 & 351978 & 28 \\
\hline $50-249$ & 3456 & 16 & 59680 & 25 & 336453 & 27 \\
\hline 250 ou + & 610 & 3 & 135292 & 56 & 554387 & 45 \\
\hline
\end{tabular}

Fonte: http://www.estatisticas.gpeari.mctes.pt 
Quadro IV

Caraterização económica e social das empresas, por região (NUTS II) (\%)

\begin{tabular}{|c|c|c|c|c|c|c|}
\hline \multirow{2}{*}{ Região (NUTS II) } & \multicolumn{2}{|c|}{ Total de empresas na população alvo } & \multicolumn{2}{|c|}{ Volume de Negócios } & \multicolumn{2}{|c|}{ Pessoal ao serviço } \\
\cline { 2 - 7 } & N. ${ }^{\circ}$ & $\%$ & Milhões de euros & $\%$ & N. ${ }^{\circ}$ & $\%$ \\
\hline Norte & 9705 & 45 & 53186 & 22 & 463019 & 37 \\
\hline Centro & 4736 & 22 & 22227 & 9 & 216786 & 17 \\
\hline Lisboa & 5125 & 24 & 149240 & 62 & 460524 & 37 \\
\hline Alentejo & 923 & 4 & 6477 & 3 & 45141 & 4 \\
\hline Algarve & 434 & 2 & 1266 & 1 & 16193 & 1 \\
\hline Açores & 317 & 1 & 2514 & 1 & 18873 & 2 \\
\hline Madeira & 328 & 2 & 6691 & 3 & 22283 & 2 \\
\hline
\end{tabular}

Fonte: http://www.estatisticas.gpeari.mctes.pt

volume de negócios. Por outro lado, o facto de a região Centro ter um número de empresas semelhante ao da região de Lisboa ( $22 \%$ contra $24 \%$ ), não tem tradução no volume de negócios de Portugal (9\%). A leitura destes resultados deve ter em atenção que se consideram todos os setores de atividade (indústria e serviços) e não apenas a indústria transformadora, vincando quer a importância crescente dos serviços na economia nacional, quer as caraterísticas estruturais da indústria transformadora (pequena dimensão, especialização em setores de menor valor acrescentado, baixa instrução da mão-de-obra e dos empresários, fraca capacidade de alterar processos produtivos e de realizar investimentos que permitam a ascensão na cadeia de valor) (GAMA, 2004).
A análise das transformações que as empresas portuguesas têm experimentado na última década no sentido de serem competitivas considera o papel que, quer a inovação tecnológica (de produto e/ou processo) quer não tecnológica (de organização e/ou marketing), têm vindo a assumir nas estratégias das empresas. Os resultados do CIS 2008 indicam que para o país, 58\% das empresas realizaram atividades de inovação no período de 2006-2008 (Figura 3). A leitura por setor evidencia que nos serviços a percentagem de empresas com atividades de inovação é superior à registada na indústria (64\% contra $54 \%$ ).

Considerando a indústria transformadora sublinha-se que o setor das indústrias têxteis, vestuário e couro foi o único em que as empresas que não realiza-

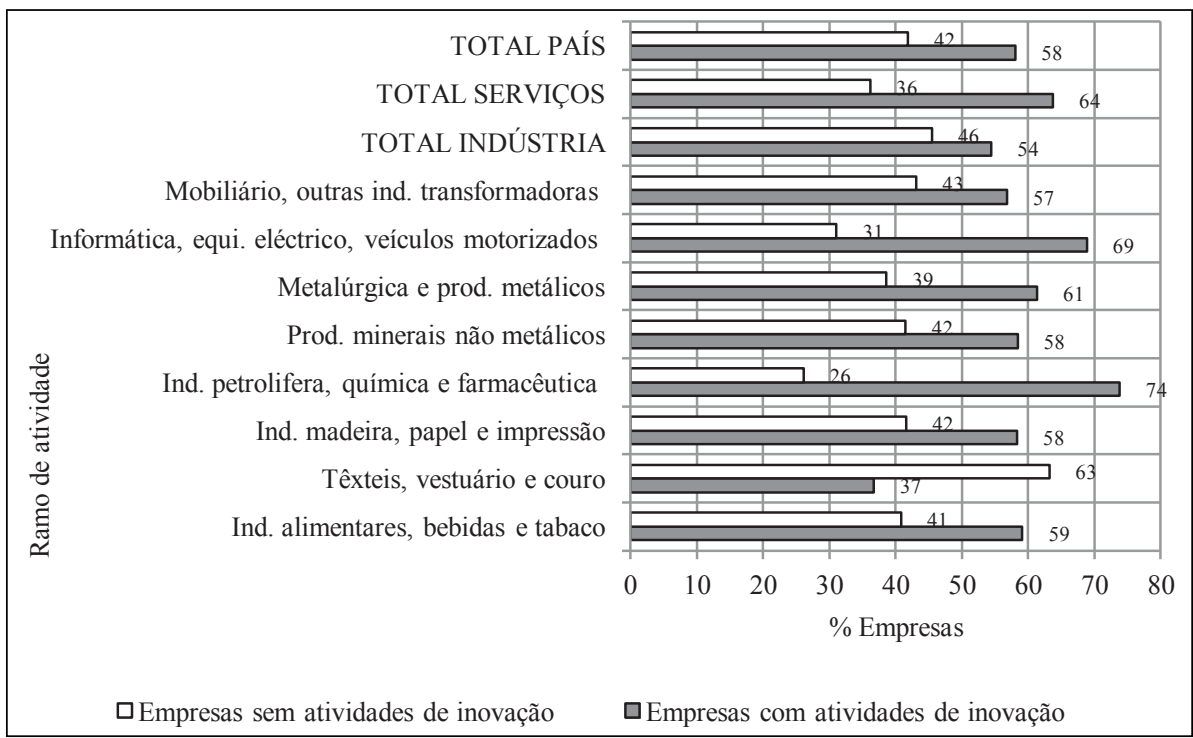

Figura 3

Empresas com e sem atividades de inovação por ramo de atividade (\%)

Fonte: http://www.estatisticas.gpeari.mctes.pt 


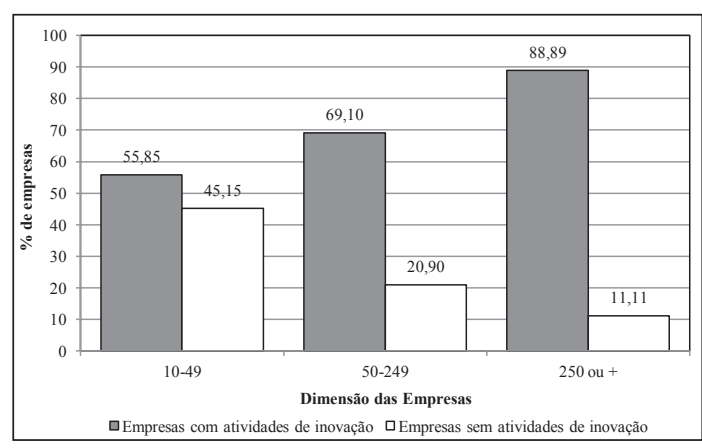

Figura 4

Empresas com e sem atividades de inovação por escalões de dimensão (\%) Fonte: http://www.estatisticas.gpeari.mctes.pt

ram atividades de inovação superam as que realizaram inovação (63\% contra 37\%). Dos setores que realizaram inovação, destacam-se as indústrias petrolíferas, químicas e farmacêuticas (74\%), informática, equipamento elétrico e veículos motorizados (69\%) e metalurgia e produtos metálicos (61\%). Estes dados parecem indicar uma mudança no perfil de especialização da indústria transformadora portuguesa e a consolidação de um modelo industrial em setores de maior valor acrescentado, a par da qualificação de ramos que têm sido a base do processo de industrialização desde o pós-guerra (produtos minerais não metálicos, mobiliário, indústrias alimentares e bebidas).

O efeito dimensão parece ser decisivo para a inovação, uma vez que as grandes empresas (250 ou mais empregados) realizaram maioritariamente atividades de inovação (cerca de 90\%) (Figura 4). Também as médias empresas (50 e 249 empregados) apresentam um valor mais expressivo ao nível da inovação (cerca de $70 \%$ ). No caso das pequenas empresas (10 a 49 empregados) a percentagem das empresas inovadoras desce para $56 \%$.

Territorialmente sublinha-se que a região de Lisboa é aquela em que maior número de empresas realiza atividades de inovação (67\%) (Figura 5). A região Norte, pelo contrário, regista um equilíbrio entre as empresas

Quadro Va

Atividades de inovação das empresas com atividades de inovação tecnológica, por ramo de atividade (\%)

\begin{tabular}{|c|c|c|c|c|c|}
\hline \multicolumn{2}{|r|}{ Atividades Económicas (CAE) } & $\begin{array}{c}\begin{array}{c}\text { Realização de } \\
\text { Atividades de I\&D } \\
\text { (I\&D intramuros) }\end{array} \\
\%\end{array}$ & \begin{tabular}{|c|}
$\begin{array}{c}\text { Aquisição externa de } \\
\text { I\&D (I\&D extramuros) }\end{array}$ \\
$\%$ \\
\end{tabular} & \begin{tabular}{|c} 
Aquisição de \\
maquinaria, equipamento \\
e software
\end{tabular} & \begin{tabular}{|c|}
$\begin{array}{c}\text { Aquisição de outros } \\
\text { conhecimentos } \\
\text { externos }\end{array}$ \\
$\%$ \\
\end{tabular} \\
\hline 10 a 12 & Ind. alimentares, bebidas e tabaco & 31 & 13 & 73 & 7 \\
\hline 13 a 15 & Têxteis, vestuário e couro & 37 & 14 & 64 & 17 \\
\hline 16 a 18 & Ind. madeira, papel e impressão & 39 & 17 & 83 & 17 \\
\hline 19 a 22 & Ind. petrolífera, química e farmacêutica & 57 & 25 & 70 & 21 \\
\hline 23 & Prod. minerais não metálicos & 46 & 27 & 79 & 18 \\
\hline 24 a 25 & Metalúrgica e prod. metálicos & 42 & 17 & 75 & 17 \\
\hline 26 a 30 & Informática, equip. elétrico, veículos motorizados & 58 & 31 & 79 & 14 \\
\hline 31 a 33 & Mobiliário, outras ind. transformadoras & 39 & 16 & 67 & 16 \\
\hline 05 a 39 & Total Indústria & 42 & 19 & 73 & 16 \\
\hline 46 a 86 & Total Serviços & 47 & 27 & 72 & 25 \\
\hline & TOTAL NACIONAL & 44 & 23 & 73 & 20 \\
\hline
\end{tabular}

Fonte: http://www.estatisticas.gpeari.mctes.pt

Quadro Vb

Atividades de inovação das empresas com atividades de inovação tecnológica, por ramo de atividade (\%)

\begin{tabular}{|c|l|c|c|c|}
\hline \multicolumn{2}{|c|}{ Atividades Económicas (CAE) } & Formação & Atividades de marketing & Outros procedimentos \\
\cline { 3 - 5 } & $\%$ & $\%$ & $\%$ \\
\hline 10 a 12 & Ind. alimentares, bebidas e tabaco & 52 & 23 & 24 \\
\hline 13 a 15 & Têxteis, vestuário e couro & 36 & 23 & 29 \\
\hline 16 a 18 & Ind. madeira, papel e impressão & 50 & 28 & 25 \\
\hline 19 a 22 & Ind. petrolífera, química e farmacêutica & 55 & 36 & 43 \\
\hline 23 & Prod. minerais não metálicos & 42 & 28 & 27 \\
\hline 24 a 25 & Metalúrgica e prod. metálicos & 51 & 22 & 31 \\
\hline 26 a 30 & Informática, equip. elétrico, veículos motorizados & 67 & 31 & 42 \\
\hline 31 a 33 & Mobiliário, outras ind. transformadoras & 43 & 34 & 27 \\
\hline 05 a 39 & Total Indústria & 49 & 27 & 31 \\
\hline 46 a 86 & Total Serviços & 64 & 36 & 33 \\
\hline \multicolumn{2}{|c|}{ TOTAL NACIONAL } & 55 & 30 & 32 \\
\hline
\end{tabular}

Fonte: http://www.estatisticas.gpeari.mctes.pt 
que realizam e as que não realizam atividades de inovação ( $52 \%$ contra $48 \%$ ). Os resultados devem contudo ser interpretados considerando as diferentes estruturas produtivas. No caso das regiões de Lisboa, Algarve e Madeira domina o setor dos serviços, sendo que a região Norte apresenta uma matriz industrial (indústria transformadora).

Um segundo vetor de análise considera as atividades das empresas com atividades de inovação tecnológica. 0 elemento estrutural que resulta da análise dos resultados destaca a importância da aquisição de maquinaria, equipamento e software nas atividades de inovação realizadas pelas empresas (Quadros Va e b). Este comportamento é comum a todos os setores de atividade da indústria transformadora. Por outro lado, a realização de atividades de I\&D (intramuros e extramuros) assume também importância nos setores das indústrias petrolíferas, química e farmacêutica e da informática, equipamento elétrico e veículos motorizados. As atividades de formação e de marketing têm também expressividade nestes setores, mesmo sendo menor o número de empresas no caso das atividades de marketing, quer em relação aos setores anteriormente referidos quer também em relação às indústrias do mobiliário, no caso das atividades de marketing. Estes dados traduzem não apenas a alteração do padrão de especialização da indústria portuguesa, como também a qualificação dos setores tradicionais, tal como os valores da realização de atividades de I\&D indicam (Quadros Va e b).

A consideração dos valores das despesas por atividade de inovação reforça a análise realizada e a centralidade que a aquisição de maquinaria, equipamento e software, por um lado, e da despesa em I\&D, por outro, têm nas empresas. Um maior número de empresas dos setores das indústrias petrolíferas, química farmacêutica e da informática, equipamento elétrico e veículos motorizados efetuam despesa em atividades de I\&D, sendo que nas indústrias dos produtos minerais não metálicos e do mobiliário a maior despesa direciona-se para a aquisição de maquinaria, equipamento e software.

A despesa efetuada em atividades de inovação tendo em atenção a dimensão da empresa indica não só que um número mais expressivo de maiores empresas realiza despesa em atividades de I\&D (39\%), como também que as pequenas e médias empresas valorizam sobretudo a aquisição de maquinaria, equipamento e software (63\%) (Quadro VII).

Por outro lado, as empresas das regiões de Lisboa e Norte são as que mais gastam em atividades de I\&D (48\% e $34 \%$, respetivamente) (Quadro VIII). As empresas

Quadro VI

Despesa por atividade de inovação (\%)

\begin{tabular}{|c|c|c|c|c|c|}
\hline \multicolumn{2}{|r|}{ Atividades Económicas (CAE) } & $\begin{array}{c}\text { Despesa em I\&D } \\
\text { (I\&D intramuros) }\end{array}$ & $\begin{array}{c}\begin{array}{c}\text { Despesa em aquisição } \\
\text { de I\&D (I\&D } \\
\text { extramuros) }\end{array} \\
\%\end{array}$ & $\begin{array}{l}\text { Aquisição de maquinaria, } \\
\text { equipamento e software }\end{array}$ & $\begin{array}{c}\begin{array}{c}\text { Aquisição de outros } \\
\text { conhecimentos } \\
\text { externos }\end{array} \\
\% \\
\end{array}$ \\
\hline 10 a 12 & Ind. alimentares, bebidas e tabaco & 14 & 3 & 81 & 2 \\
\hline 13 a 15 & Têxteis, vestuário e couro & 28 & 8 & 63 & 2 \\
\hline 16 a 18 & Ind. madeira, papel e impressão & 4 & 2 & 94 & 0 \\
\hline 19 a 22 & Ind. petrolífera, química e farmacêutica & 55 & 24 & 19 & 2 \\
\hline 23 & Prod. minerais não metálicos & 24 & 6 & 69 & 1 \\
\hline 24 a 25 & Metalúrgica e prod. metálicos & 33 & 2 & 64 & 1 \\
\hline 26 a 30 & Informática, equip. elétrico, veículos motorizados & 46 & 13 & 38 & 3 \\
\hline 31 a 33 & Mobiliário, outras ind. transformadoras & 33 & 2 & 65 & 1 \\
\hline 05 a 39 & Total Indústria & 26 & 8 & 65 & 1 \\
\hline 46 a 86 & Total Serviços & 46 & 12 & 38 & 4 \\
\hline & TOTAL NACIONAL & 35 & 10 & 53 & 3 \\
\hline
\end{tabular}

Fonte: http://www.estatisticas.gpeari.mctes.pt

Quadro VII

Despesa em inovação, por dimensão da empresa (\%)

\begin{tabular}{|c|c|c|c|c|}
\hline \multirow{2}{*}{$\begin{array}{c}\text { Dimensão ( }{ }^{\circ} \text { de } \\
\text { empregados) }\end{array}$} & $\begin{array}{c}\text { Despesa em I\&D } \\
\text { (I\&D intramuros) }\end{array}$ & $\begin{array}{c}\text { Despesa em aquisição } \\
\text { de I\&D (I\&D extramuros) }\end{array}$ & $\begin{array}{c}\text { Aquisição de maquinaria, } \\
\text { equipamento e software }\end{array}$ & $\begin{array}{c}\text { Aquisição de outros } \\
\text { conhecimentos externos }\end{array}$ \\
\hline $10-49$ & $\%$ & $\%$ & $\%$ & $\%$ \\
\hline $50-249$ & 27 & 8 & 63 & 2 \\
\hline 250 ou + & 32 & 5 & 62 & 1 \\
\hline
\end{tabular}

Fonte: http://www.estatisticas.gpeari.mctes.pt 
das regiões do Algarve, Centro e Alentejo apresentam elevada despesa em aquisição de maquinaria, equipamento e software. Estes resultados traduzem uma aposta na qualificação do tecido produtivo e a procura de criar/reforçar a capacidade das empresas.

Como terceiro elemento de abordagem analisase o tipo de inovação tecnológica (produto e processo) que as empresas realizam. Destaca-se, desde logo, para a indústria transformadora a elevada percentagem de empresas com inovação tecnológica (Quadro IX). Com efeito, só no ramo das indústrias têxteis, vestuário e couro as empresas sem inovação tecnológica são em maior número (69\%). Nos restantes ramos, as indústrias petrolífera, química e farmacêutica e da informática, equipamento elétrico e veículos motorizados apresentam elevadas percentagens de empresas com inovação tecnológica (70\% e $64 \%$, respetivamente). De forma mais específica, estes dois ramos realizaram inovações de processo ( $56 \%$ e $54 \%$, respetivamente) e/ou de produto $(56 \%$ e $48 \%)$.

Estes resultados indicam a importância que a inovação tecnológica tem para as empresas e a necessidade de continuamente se investir não apenas em máquinas, equipamento e software, mas também em $I \& D$, criando e melhorando produtos, estratégias que são fundamentais para a sobrevivência das empresas no atual contexto de competição à escala global.

O fator dimensão evidencia-se também ao analisar a inovação tecnológica, já que $82 \%$ das empresas com mais de 250 empregados referem ter realizado este tipo de inovação, privilegiando quer a inovação de processo (76\%), quer de produto (62\%) (Quadro X). Registase um comportamento menos expressivo nas empresas de menor dimensão (pequenas), com cerca de metade a revelarem ter realizado inovação tecnológica (47\%). Sublinha-se ainda o facto de que a percentagem de empresas com inovação de processo ser sempre maior que com inovação de produto, independentemente da dimensão as empresas.

A análise por região indica valores semelhantes de empresas com inovação tecnológica para todas as regiões, mesmo registando Lisboa um valor ligeiramente superior em relação ao observado pelas restantes regiões ( $55 \%$ contra $44 \%$ no caso da região Norte).

Considerando o volume de negócios das empresas com inovação de produto destaca-se o facto de o

Quadro VIII

Despesa em inovação, por região (NUTS II) (\%)

\begin{tabular}{|c|c|c|c|c|}
\hline \multirow{2}{*}{ Região (NUTS II) } & $\begin{array}{c}\text { Despesa em I\&D } \\
\text { (I\&D intramuros) }\end{array}$ & $\begin{array}{c}\text { Despesa em aquisição de } \\
\text { I\&D (I\&D extramuros) }\end{array}$ & $\begin{array}{c}\text { Aquisição de maquinaria, } \\
\text { equipamento e software }\end{array}$ & $\begin{array}{c}\text { Aquisição de outros } \\
\text { conhecimentos externos }\end{array}$ \\
\cline { 2 - 5 } & $\%$ & $\%$ & $\%$ & $\%$ \\
\hline Norte & 34 & 11 & 50 & 79 \\
\hline Centro & 16 & 4 & 39 & 2 \\
\hline Lisboa & 48 & 11 & 85 & 1 \\
\hline Alentejo & 11 & 3 & 74 & 3 \\
\hline Algarve & 19 & 4 & 60 & 0 \\
\hline Açores & 13 & 26 & 42 & 4 \\
\hline Madeira & 14 & 41 & & 5 \\
\hline
\end{tabular}

Fonte: http://www.estatisticas.gpeari.mctes.pt

Quadro IX

Empresas com inovação tecnológica, por ramo de atividade (\%)

\begin{tabular}{|c|c|c|c|c|}
\hline \multicolumn{2}{|r|}{ Atividades Económicas (CAE) } & \multirow{2}{*}{$\begin{array}{c}\begin{array}{c}\text { Empresas com Inovação } \\
\text { Tecnológica* }\end{array} \\
51\end{array}$} & \multirow{2}{*}{\begin{tabular}{|c|}
$\begin{array}{c}\text { Empresas com Inovação } \\
\text { de Produto }\end{array}$ \\
33
\end{tabular}} & \multirow{2}{*}{\begin{tabular}{|c|}
$\begin{array}{c}\text { Empresas com Inovação } \\
\text { de Processo }\end{array}$ \\
44
\end{tabular}} \\
\hline 10 a 12 & Ind. alimentares, bebidas e tabaco & & & \\
\hline 13 a 15 & Têxteis, vestuário e couro & 31 & 18 & 26 \\
\hline 16 a 18 & Ind. madeira, papel e impressão & 50 & 31 & 46 \\
\hline 19 a 22 & Ind. petrolífera, química e farmacêutica & 70 & 56 & 56 \\
\hline 23 & Prod. minerais não metálicos & 55 & 31 & 45 \\
\hline 26 a 30 & Informática, equip. elétrico, veículos motorizados & 64 & 48 & 54 \\
\hline 31 a 33 & Mobiliário, outras ind. transformadoras & 52 & 40 & 41 \\
\hline 05 a 39 & Total Indústria & 48 & 31 & 40 \\
\hline 46 a 86 & Total Serviços & 54 & 38 & 44 \\
\hline \multicolumn{2}{|r|}{ TOTAL NACIONAL } & 50 & 34 & 42 \\
\hline
\end{tabular}

Fonte: http://www.estatisticas.gpeari.mctes.pt 
Quadro X

Empresas com inovação tecnológica, por dimensão (\%)

\begin{tabular}{|c|c|c|c|}
\hline $\begin{array}{c}\text { Dimensão ( }{ }^{\circ} \\
\text { de empregados) }\end{array}$ & $\begin{array}{c}\text { Empresas com } \\
\text { Inovação } \\
\text { Tecnologica* }\end{array}$ & $\begin{array}{c}\text { Empresas com } \\
\text { Inovação } \\
\text { de Produto }\end{array}$ & $\begin{array}{c}\text { Empresas com } \\
\text { Inovação } \\
\text { de Processo }\end{array}$ \\
\hline $10-49$ & 47 & 31 & 39 \\
\hline $50-249$ & 63 & 45 & 52 \\
\hline 250 ou + & 82 & 62 & 76 \\
\hline
\end{tabular}

Fonte: http://www.estatisticas.gpeari.mctes.pt

setor da informática, equipamento elétrico e veículos motorizados ser aquele que mais beneficia com o lançamento de produtos novos para o mercado (com 24\% do volume de negócios estar associado a estes produtos) (Figura 6). Por outro lado, o setor da indústria petrolífera, química e farmacêutica é o que menos beneficia com produtos novos para o mercado. Considerando todos os setores de atividade pode concluir-se que, do volume total de negócios uma parte está associada à criação de novos produtos, quer para o mercado quer para a empresa, mesmo tendo em atenção que $3 / 4$ ou mais do volume de negócios estar relacionado com produtos não modificados.

O efeito dimensão aparece também ao ser considerado o tipo de inovação de produto, uma vez são as empresas de maior dimensão as que apresentam maiores volumes de negócio com produtos novos para o mercado (Figura 7).

A análise por região destaca o tipo de atividades, a especialização e a trajetória industrial, já que a região do Alentejo e a Região Autónoma do Açores são as que maiores percentagens do volume de negócios estão associadas a empresas com produtos novos para o mercado.

Outro vetor de análise para as empresas com atividades de inovação tecnológica considera o apoio financeiro público para a inovação. Regista-se desde logo a importância que a administração central tem para as atividades de inovação tecnológica, uma vez que somente no setor dos produtos minerais não metálicos a União Europeia aparece como a instituição com maior importância para as empresas (Figura 9). Para os ramos da indústria petrolífera, química e farmacêutica e da informática, equipamento elétrico e veículos motorizados a percentagem de empresas apoiadas pela administração central é mais do dobro da apoiada pela União Europeia.

Por outro lado, a importância da dimensão das empresas traduz-se na valorização do apoio prove-

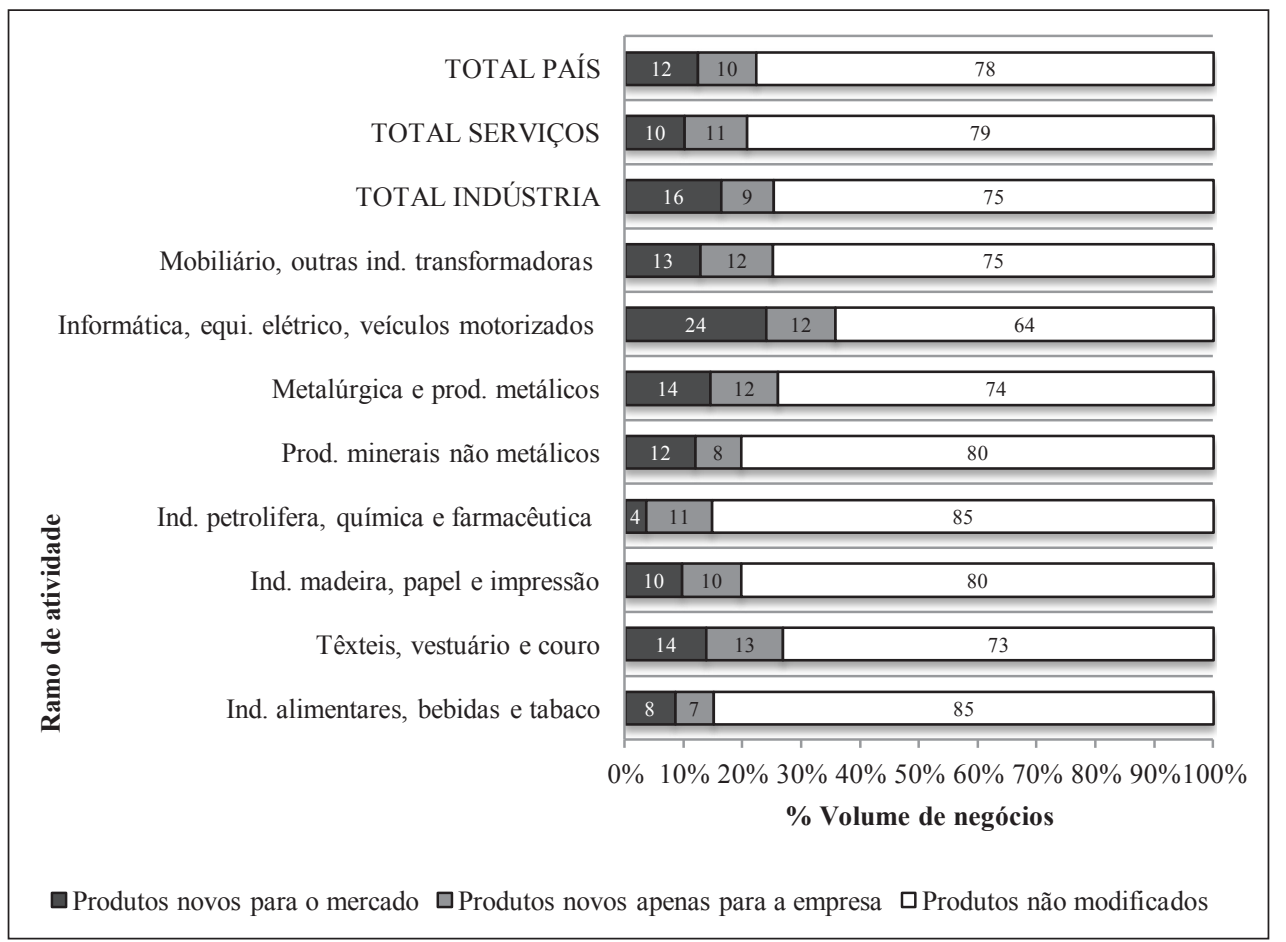

Figura 6

Volume de negócios nas empresas, por produto (\%)

Fonte: http://www.estatisticas.gpeari.mctes.pt 


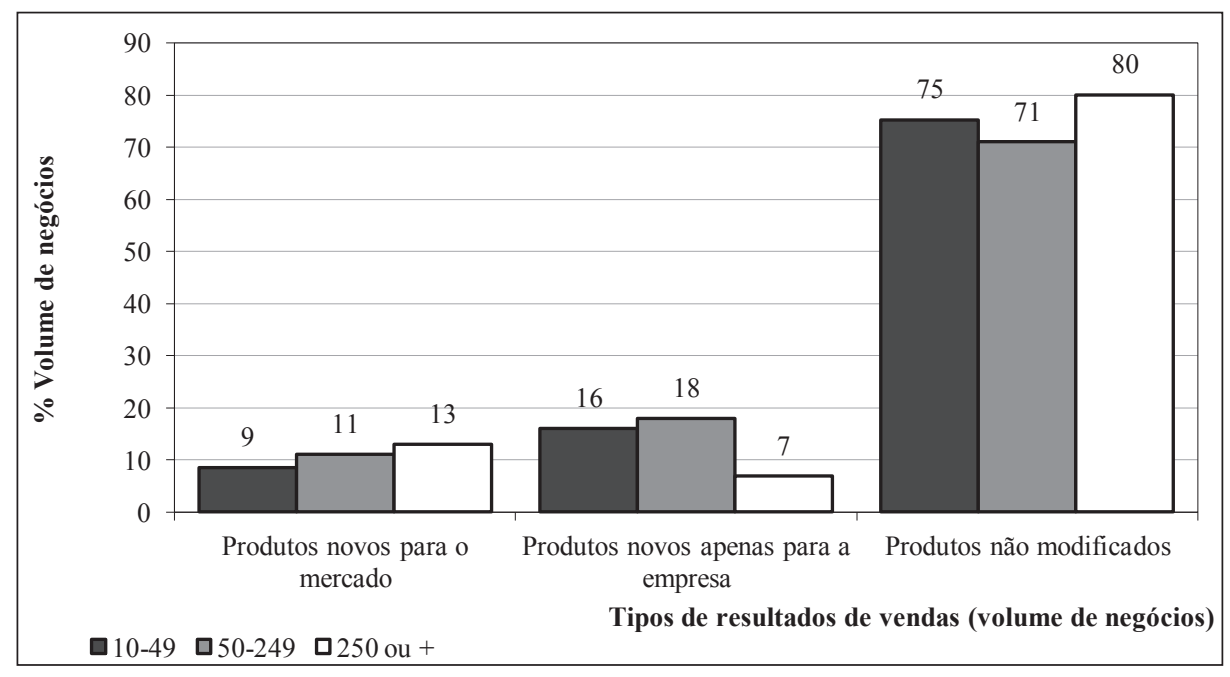

\section{Figura 7}

Volume de negócios nas empresas, por dimensão (\%)

Fonte: http://www.estatisticas.gpeari.mctes.pt

niente quer da administração central, quer da União Europeia (Figura 10). 0 apoio financeiro à inovação através da administração local não traduz o efeito dimensão, sendo ainda reduzido o número de empresas que recorre a esta fonte ( 1 ou $2 \%$ das empresas). Acresce que, territorialmente não se verificam diferenças significativas entre as regiões, sendo que apenas na Região Autónoma dos Açores o apoio financeiro à inovação está maioritariamente associado à administração local. Também na Região Autónoma da Madeira esta fonte tem um papel importante, mesmo sendo menor que os outros dois tipos de fontes de apoio financeiro (administração central e União Europeia).

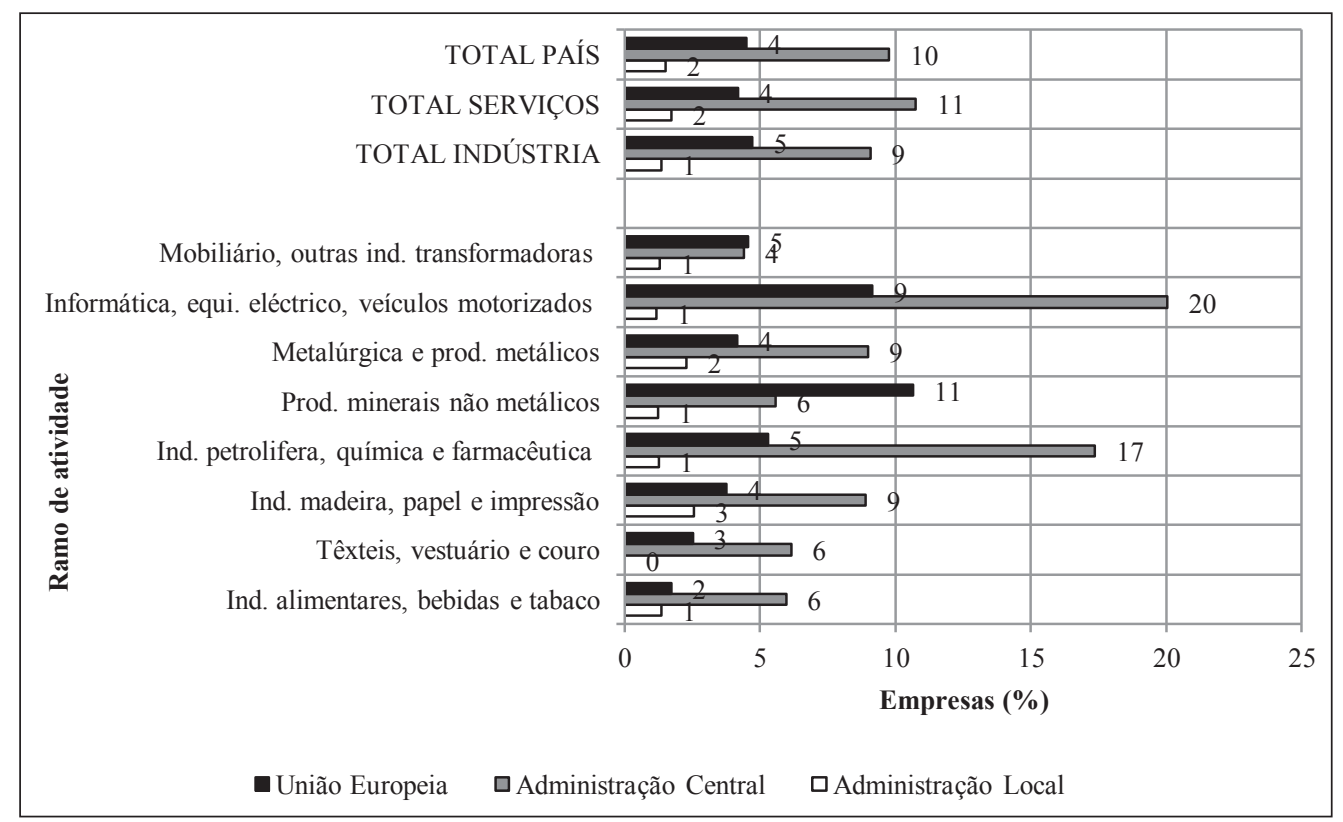

Figura 9

Apoio financeiro público à inovação, por ramo (\%)

Fonte: http://www.estatisticas.gpeari.mctes.pt 


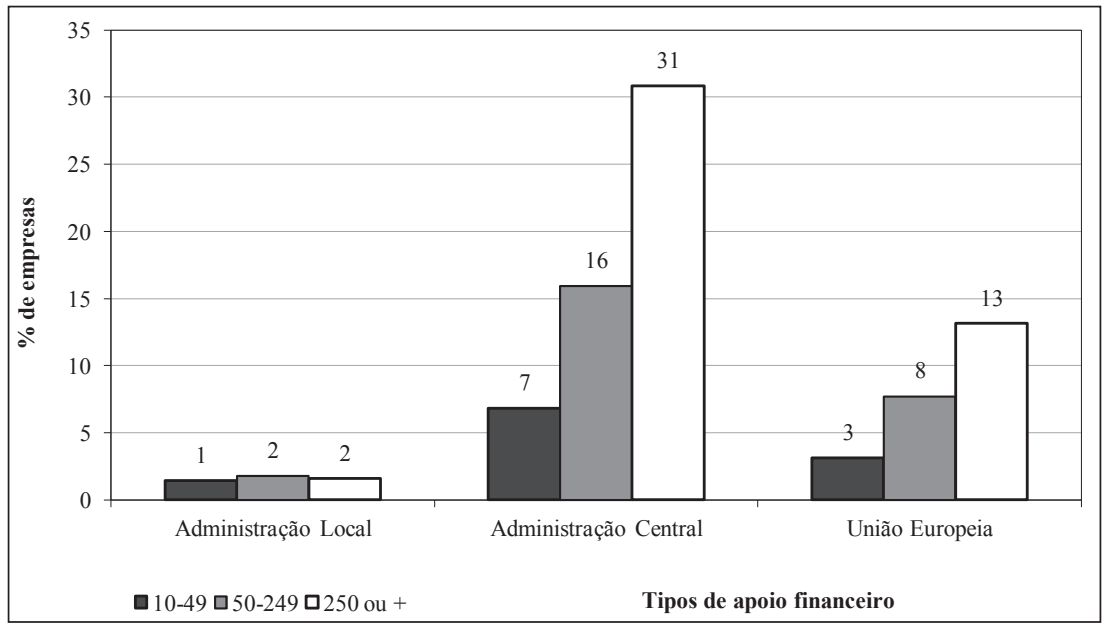

Figura 10

Apoio financeiro público à inovação, por dimensão da empresa (\%)

Fonte: http://www.estatisticas.gpeari.mctes.pt

Estes resultados traduzem a forma de organização administrativa do Estado português e a valorização da dimensão central face à local/regional.

A complexidade associada a qualquer projeto de inovação realizado pelas empresas com atividades de inovação tecnológica implica a mobilização de um conjunto de fontes de informação, quer sejam internas à empresa, adquiridas no mercado, institucionais ou outras fontes (Quadros Xla e XIb). Os dados recolhidos indicam uma realidade dupla, isto é, importância das fontes internas à própria empresa ou ao grupo a que pertence e também de mercado (em particular ligadas aos fornecedores e clientes ou consumidores), e, por outro lado, reduzida procura de fontes institucionais (universidades, institutos politécnicos ou suas instituições de interface e laboratórios do Estado ou outros organismos públicos de I\&D). Acresce que não se verificam diferenças ao serem analisados os valores por setor de indústria. Este comportamento traduz uma das caraterísticas estruturais na indústria portuguesa que valoriza pouco as instituições de investigação superior. As políticas públicas das décadas mais recentes têm procurado modificar este quadro, mantendo-se contudo um afastamento entre uma das principais fontes de criação de conhecimento e o desenvolvimento e aplicação em inovações sobretudo de produto e processo.

Os dados da cooperação das empresas com atividades de inovação tecnológica com outras empresas

\section{Quadro Xla}

Fontes de informação para realização de projetos de inovação pelas empresas com atividades de inovação tecnológica, por atividade económica (\%)

\begin{tabular}{|c|c|c|c|c|c|c|}
\hline \multirow{3}{*}{\multicolumn{2}{|c|}{ Atividades Económicas (CAE) }} & \multirow{3}{*}{\begin{tabular}{|c|} 
Fontes internas \\
$\begin{array}{c}\text { Dentro da própria } \\
\text { empresa ou no } \\
\text { grupo a que } \\
\text { pertence }\end{array}$ \\
$\%$
\end{tabular}} & \multicolumn{4}{|c|}{ Fontes de mercado } \\
\hline & & & \multirow{2}{*}{$\begin{array}{c}\text { Fornecedores de } \\
\text { equipamento, } \\
\text { material, } \\
\text { componentes ou } \\
\text { software } \\
\% \\
\end{array}$} & \multirow{2}{*}{$\begin{array}{c}\begin{array}{c}\text { Clientes } \\
\text { ou } \\
\text { consumidores }\end{array} \\
\% \\
\%\end{array}$} & \multirow{2}{*}{$\begin{array}{c}\text { Concorrentes ou } \\
\text { outras empresas } \\
\text { do mesmo sector }\end{array}$} & \multirow{2}{*}{$\begin{array}{c}\begin{array}{c}\text { Consultores } \\
\text { ou empresas } \\
\text { privadas } \\
\text { de I\&D }\end{array} \\
\% \\
\end{array}$} \\
\hline & & & & & & \\
\hline 10 a 12 & Ind. alimentares, bebidas e tabaco & 21 & 19 & 24 & 12 & 13 \\
\hline 13 a 15 & Têxteis, vestuário e couro & 21 & 17 & 19 & 9 & 4 \\
\hline 16 a 18 & Ind. madeira, papel e impressão & 25 & 21 & 26 & 11 & 5 \\
\hline 19 a 22 & Ind. petrolífera, química e farmacêutica & 43 & 20 & 33 & 16 & 5 \\
\hline 23 & Prod. minerais não metálicos & 35 & 27 & 20 & 7 & 5 \\
\hline 24 a 25 & Metalúrgica e prod. metálicos & 29 & 17 & 31 & 9 & 4 \\
\hline 26 a 30 & Informática, equip. elétrico, veículos motorizados & 52 & 20 & 44 & 14 & 6 \\
\hline 31 a 33 & Mobiliário, outras ind. transformadoras & 21 & 16 & 23 & 8 & 5 \\
\hline 05 a 39 & Total Indústria & 29 & 19 & 27 & 10 & 6 \\
\hline 46 a 86 & Total Serviços & 39 & 18 & 29 & 12 & 8 \\
\hline & TOTAL NACIONAL & 33 & 19 & 27 & 11 & 7 \\
\hline
\end{tabular}

Fonte: http://www.estatisticas.gpeari.mctes.pt 
ou instituições reforçam este quadro (Quadro XII). Com efeito, cerca de $1 / 4$ das empresas revelam cooperar no sentido de inovarem, sendo que os ramos das indústrias informáticas, equipamento elétrico e veículos motorizados e da indústria petrolífera, química e farmacêutica apresentam um número superior de empresas que cooperam com outras empresas ou instituições (38\% e $33 \%$, respetivamente). Também o setor dos produtos minerais não metálicos se destaca neste domínio, uma vez que $33 \%$ das empresas apresentam este tipo de comportamento.

Os parceiros da cooperação são fundamentalmente os fornecedores de equipamento, material, componentes ou software e os clientes ou fornecedores (Quadros XIIla e XIIIb). Nos dois ramos que temos vindo a destacar, as outras empresas do grupo e as universidades, institutos politécnicos ou suas instituições de interface são também parceiros preferenciais. O setor dos produtos minerais não metálicos apresenta um comportamento similar. Estes resultados permitem refletir sobre as estratégias que as empresas utilizam para inovarem e a natureza muitas vezes passiva como abordam os mercados ao não procurarem fontes e parceiros que lhes permitam antecipar as tendências de mercado.

Um último elemento de análise considera para as empresas com inovação tecnológica a introdução de inovação não tecnológica (de marketing e/ou organizacional) (Quadro XIV). A importância que este tipo de inovação tem para as empresas está expresso nos valores observados. Efetivamente, mais de metade das empresas revela ter realizado no período em análise inovação organizacional ou de marketing, não existindo diferenças significativas para os diferentes ramos de atividade.

Quadro XIb

Fontes de informação para realização de projetos de inovação pelas empresas com atividades de inovação tecnológica, por atividade económica (\%)

\begin{tabular}{|c|c|c|c|c|c|c|}
\hline \multirow{3}{*}{\multicolumn{2}{|c|}{ Atividades Económicas (CAE) }} & \multicolumn{2}{|c|}{ Fontes institucionais } & \multicolumn{3}{|c|}{ Outras fontes } \\
\hline & & $\begin{array}{c}\text { Universidades, } \\
\text { institutos politécnicos } \\
\text { ou suas instituições } \\
\text { de interface }\end{array}$ & $\begin{array}{l}\text { Laboratórios do } \\
\text { Estado ou outros } \\
\text { organismos } \\
\text { públicos de I\&D }\end{array}$ & \begin{tabular}{|} 
Conferências, \\
feiras e \\
exposições
\end{tabular} & \begin{tabular}{|c|} 
Revistas científicas \\
e livros técnicos/ \\
profissionais
\end{tabular} & $\begin{array}{c}\text { Associações } \\
\text { profissionais } \\
\text { ou } \\
\text { empresariais }\end{array}$ \\
\hline & & $\%$ & $\%$ & $\%$ & $\%$ & $\%$ \\
\hline 10 a 12 & Ind. alimentares, bebidas e tabaco & 5 & 4 & 5 & 6 & 7 \\
\hline 13 a 15 & Têxteis, vestuário e couro & 2 & 1 & 10 & 5 & 4 \\
\hline 16 a 18 & Ind. madeira, papel e impressão & 2 & 1 & 16 & 7 & 8 \\
\hline 19 a 22 & Ind. petrolífera, química e farmacêutica & 6 & 5 & 13 & 8 & 7 \\
\hline 23 & Prod. minerais não metálicos & 2 & 3 & 15 & 5 & 5 \\
\hline 24 a 25 & Metalúrgica e prod. metálicos & 2 & 2 & 11 & 5 & 3 \\
\hline 26 a 30 & Informática, equip. elétrico, veículos motorizados & 5 & 3 & 20 & 8 & 5 \\
\hline 31 a 33 & Mobiliário, outras ind. transformadoras & 2 & 1 & 17 & 8 & 5 \\
\hline 05 a 39 & Total Indústria & 4 & 2 & 12 & 6 & 5 \\
\hline 46 a 86 & Total Serviços & 4 & 3 & 10 & 8 & 8 \\
\hline & TOTAL NACIONAL & 4 & 3 & 11 & 7 & 6 \\
\hline
\end{tabular}

Fonte: http://www.estatisticas.gpeari.mctes.pt

Quadro XII

Empresas com cooperação com outras empresas ou instituições no âmbito das suas atividades de inovação tecnológica (\%)

\begin{tabular}{|c|l|c|}
\hline \multicolumn{2}{|c|}{ Atividades Económicas (CAE) } & $\begin{array}{c}\text { Empresas com cooperação } \\
\text { para a inovação }\end{array}$ \\
\cline { 3 - 3 } & $\%$ \\
\hline 10 a 12 & Ind. alimentares, bebidas e tabaco & 23 \\
\hline 13 a 15 & Têxteis, vestuário e couro & 22 \\
\hline 16 a 18 & Ind. madeira, papel e impressão & 22 \\
\hline 19 a 22 & Ind. petrolífera, química e farmacêutica & 33 \\
\hline 23 & Prod. minerais não metálicos & 33 \\
\hline 24 a 25 & Metalúrgica e prod. metálicos & 25 \\
\hline 26 a 30 & Informática, equip. elétrico, veículos motorizados & 38 \\
\hline 31 a 33 & Mobiliário, outras ind. transformadoras & 19 \\
\hline 05 a 39 & Total Indústria & 27 \\
\hline 46 a 86 & Total Serviços & 31 \\
\hline & TOTAL NACIONAL & 29 \\
\hline
\end{tabular}

Fonte: http://www.estatisticas.gpeari.mctes.pt 
Por outro lado, estes resultados são ainda reforçados ao referirmos que das empresas que não realizam inovação tecnológica existem algumas que indicam rea- lizar inovação organizacional e/ou de marketing. São sobretudo os setores mais tradicionais (indústrias alimentares, bebidas e tabaco, madeira e metalurgia e

Quadro XIIIa

Tipo de parceiro de cooperação das empresas no âmbito das suas atividades de inovação tecnológica (\%)

\begin{tabular}{|c|c|c|c|c|c|}
\hline \multicolumn{2}{|r|}{ Atividades Económicas (CAE) } & \begin{tabular}{|c|}
$\begin{array}{c}\text { Outras empresas } \\
\text { do grupo }\end{array}$ \\
$\%$ \\
\end{tabular} & $\begin{array}{c}\text { Fornecedores de } \\
\text { equipamento, material, } \\
\text { componentes ou software } \\
\% \\
\end{array}$ & \begin{tabular}{|c|}
$\begin{array}{c}\text { Clientes ou } \\
\text { consumidores }\end{array}$ \\
$\%$ \\
\end{tabular} & \begin{tabular}{|c|}
$\begin{array}{c}\text { Concorrentes ou outras } \\
\text { empresas do mesmo sector }\end{array}$ \\
$\%$ \\
\end{tabular} \\
\hline 10 a 12 & Ind. alimentares, bebidas e tabaco & 5 & 16 & 17 & 7 \\
\hline 13 a 15 & Têxteis, vestuário e couro & 3 & 18 & 17 & 8 \\
\hline 16 a 18 & Ind. madeira, papel e impressão & 3 & 19 & 16 & 6 \\
\hline 19 a 22 & Ind. petrolífera, química e farmacêutica & 13 & 25 & 23 & 10 \\
\hline 23 & Prod. minerais não metálicos & 4 & 23 & 22 & 11 \\
\hline 24 a 25 & Metalúrgica e prod. metálicos & 5 & 19 & 18 & 7 \\
\hline 26 a 30 & Informática, equip. elétrico, veículos motorizados & 14 & 28 & 24 & 10 \\
\hline 31 a 33 & Mobiliário, outras ind. transformadoras & 1 & 14 & 15 & 7 \\
\hline 05 a 39 & Total Indústria & 6 & 20 & 18 & 8 \\
\hline 46 a 86 & Total Serviços & 10 & 25 & 19 & 11 \\
\hline & TOTAL NACIONAL & 8 & 22 & 19 & 10 \\
\hline
\end{tabular}

Fonte: http://www.estatisticas.gpeari.mctes.pt

Quadro XIIIb

Tipo de parceiro de cooperação das empresas no âmbito das suas atividades de inovação tecnológica (\%)

\begin{tabular}{|c|c|c|c|c|}
\hline \multicolumn{2}{|r|}{ Atividades Económicas (CAE) } & $\begin{array}{c}\text { Consultores, empresas privadas } \\
\text { de I\&D, assoc. empresariais e/ou } \\
\text { Centros Tecnológicos } \\
\% \\
\end{array}$ & $\begin{array}{c}\begin{array}{c}\text { Univers., institutos } \\
\text { politécnicos ou suas } \\
\text { instituições de interface }\end{array} \\
\% \\
\end{array}$ & $\begin{array}{c}\text { Laboratórios do Estado } \\
\text { ou outros organismos } \\
\text { públicos de I\&D } \\
\% \\
\end{array}$ \\
\hline 10 a 12 & Ind. alimentares, bebidas e tabaco & 12 & 5 & 2 \\
\hline 13 a 15 & Têxteis, vestuário e couro & 9 & 6 & 5 \\
\hline 16 a 18 & Ind. madeira, papel e impressão & 6 & 4 & 3 \\
\hline 19 a 22 & Ind. petrolífera, química e farmacêutica & 14 & 15 & 9 \\
\hline 23 & Prod. minerais não metálicos & 10 & 12 & 11 \\
\hline 24 a 25 & Metalúrgica e prod. metálicos & 9 & 9 & 5 \\
\hline 26 a 30 & Informática, equi. elétrico, veículos motorizados & 14 & 15 & 8 \\
\hline 31 a 33 & Mobiliário, outras ind. transformadoras & 9 & 6 & 5 \\
\hline 05 a 39 & Total Indústria & 11 & 9 & 6 \\
\hline 46 a 86 & Total Serviços & 12 & 10 & 5 \\
\hline & TOTAL NACIONAL & 11 & 9 & 6 \\
\hline
\end{tabular}

Fonte: http://www.estatisticas.gpeari.mctes.pt

Quadro XIV

Empresas com inovação tecnológica que introduziram inovação não tecnológica (\%)

\begin{tabular}{|c|l|c|c|c|}
\hline \multicolumn{2}{|c|}{ Atividades Económicas (CAE) } & $\begin{array}{c}\text { com Inovação } \\
\text { Organizacional }\end{array}$ & $\begin{array}{c}\text { com Inovação } \\
\text { de Marketing }\end{array}$ & $\begin{array}{c}\text { com Inovação Organizacional } \\
\text { e Inovação de Marketing }\end{array}$ \\
\cline { 3 - 5 } & $\%$ & $\%$ & $\%$ \\
\hline 10 a 12 & Ind. alimentares, bebidas e tabaco & 53 & 61 & 41 \\
\hline 13 a 15 & Têxteis, vestuário e couro & 47 & 34 & 23 \\
\hline 16 a 18 & Ind. madeira, papel e impressão & 49 & 47 & 34 \\
\hline 19 a 22 & Ind. petrolífera, química e farmacêutica & 62 & 56 & 38 \\
\hline 23 & Prod. minerais não metálicos & 66 & 49 & 37 \\
\hline 24 a 25 & Metalúrgica e prod. metálicos & 58 & 48 & 37 \\
\hline 26 a 30 & Informática, equi. elétrico, veículos motorizados & 63 & 45 & 34 \\
\hline 31 a 33 & Mobiliário, outras ind. transformadoras & 54 & 54 & 39 \\
\hline 05 a 39 & Total Indústria & 55 & 48 & 35 \\
\hline 46 a 86 & Total Serviços & 71 & 60 & 50 \\
\hline
\end{tabular}

Fonte: http://www.estatisticas.gpeari.mctes.pt 
produtos metálicos) que revelam ter realizado inovação não tecnológica. Os valores observados são contudo menos expressivos que no caso das empresas com inovação tecnológica com inovação não tecnológica (máximo de $12 \%$ contra um mínimo de $45 \%$ ).

\section{Notas finais}

Na sequência dos anteriores inquéritos à inovação, o Community Innovation Survey 2008 assume-se cada vez mais como uma fonte para que se possa avaliar as atividades e processos de inovação em Portugal, ao nível do produto, do processo e da inovação organizacional e de marketing, bem como dos seus condicionantes, resultados e fragilidades/potencialidades.

Em primeiro lugar deve ter-se presente que o contexto socioeconómico sublinha a tendência de reforço na última década das atividades de serviços na economia portuguesa, considerando quer o pessoal ao serviço, quer o volume de negócios. A indústria transformadora é contudo a atividade que apresenta o maior número de empresas. Por outro lado, os dados refletem a importância das grandes empresas (250 ou mais empregados) na estrutura económica, representando $45 \%$ do pessoal ao serviço e $56 \%$ do volume de negócios. Territorialmente, as regiões do Norte e de Lisboa representam $69 \%$ das empresas na população alvo, $74 \%$ do pessoal ao serviço e $84 \%$ do volume de negócios.

A inovação empresarial (tecnológica e não tecnológica) é uma estratégia fundamental para $58 \%$ das empresas em Portugal, representando $54 \%$ no caso da indústria e $64 \%$ nos serviços. Por setor e considerando apenas a indústria transformadora destacam-se pelo comportamento favorável as indústrias petrolíferas, químicas e farmacêuticas e de informática, equipamento elétrico e veículos motorizados. 0 ramo das indústrias têxteis, vestuário e couro é o único em que as empresas sem atividades de inovação superam as com atividades de inovação (63\% contra $37 \%$ ). O efeito dimensão parece ser decisivo para as atividades de inovação, uma vez que cerca de 9 em cada 10 empresas com 250 ou mais empregados realiza atividades de inovação. No caso das pequenas empresas (10 a 49 empregados) apenas cerca de metade das empresas revela tal comportamento.

As atividades de inovação das empresas com atividades de inovação tecnológica privilegiam a aquisição de maquinaria, equipamento e software, sendo que a formação e a realização de atividades de I\&D intramuros são as outras formas de inovação das empresas. As empresas dos setores das indústrias petrolíferas, químicas e farmacêuticas e de informática, equipamento elétrico e veículos motorizados destacam-se na realização de atividades de I\&D intramuros, na formação e nas atividades de marketing. As empresas de pequena dimensão realizam atividades de inovação que assentam sobretudo nos fatores competitivos estáticos (materiais), sendo que as de maior dimensão privilegiam a componente dinâmica (I\&D). Por outro lado, a inovação tecnológica, quer de produto quer de processo, assume-se como a estratégia de qualificação seguida pelas empresas, sendo que apenas nas indústrias têxteis, vestuário e couro apenas cerca de $1 / 3$ das empresas realiza este tipo de inovação.

O papel do apoio financeiro público é fundamental para a inovação que as empresas realizam, sobretudo considerando a administração central. o fator dimensão das empresas assim como o setor de atividade são decisivos no aproveitamento do financiamento disponibilizado, tal como no tipo de relações que são estabelecidas com outras empresas ou instituições.

Para que as empresas possam ser competitivas têm que continuamente procurar ser inovadoras. Neste sentido é fundamental que existam políticas de contexto que, de forma concertada e articulada, possibilitem que os diferentes intervenientes no processo de inovação possam estabelecer relacionamentos que facilitem o aparecimento de inovações. Os dados do CIS 2008 traduzem quer as caraterísticas estruturais da economia portuguesa, quer uma evolução favorável nos indicadores de inovação, com o aparecimento de indústrias em setores de maior intensidade tecnológica.

\section{Bibliografia}

Gabinete de Planeamento, Estratégia, Avaliação e Relações Internacionals, Direção de Serviços de Informação Estatística EM CIÊNCIA E TeCnologia (2010) - Sumários Estatísticos CIS 2008 - Inquérito Comunitário à Inovação. Gabinete de Planeamento, Estratégia, Avaliação e Relações Internacionais, Lisboa.

GamA, Rui (2002/2004) - "Espaços de inovação no Continente português. Análise das principais alterações ocorridas na indústria durante a década de 90". Cadernos de Geografia, 21/23, Coimbra, pp. 53-65.

GAMA, Rui (2004) - Dinâmicas industriais, inovação e território. Abordagem geográfica a partir do Centro Litoral. Fundação Calouste Gulbenkian e Fundação para a Ciência e a Tecnologia, Lisboa. 
Gama, Rui e Fernandes, Ricardo (2008) - "Inovação, conhecimento e indústria em Portugal: uma análise do Community innovation survey 4 (CIS 4)". Revista Minerva, Volume 5, Número 2, Julho a Dezembro de 2008, São Paulo, pp. 217-230.

Gama, Rui e Fernandes, Ricardo (2011) - "Políticas públicas de inovação em Portugal - uma análise do QREN". Actas do VIII Colóquio de Geografia Portuguesa, Repensar a Geografia para novos desafios: Competências, investigação e acção, 26 a 29 de Outubro de 2011, Lisboa.

OCDE (2005) - Manual de Oslo, OCDE, Paris.

INE (2010) - Anuários Estatísticos (Norte, Centro, Lisboa, Alentejo, Algarve, Região Autónoma dos Açores e Região Autónoma da Madeira). INE, Lisboa.

http: / / www.gpeari.mctes.pt/archive/doc/QuadrosCIS2008_ quadros_versaoweb_25022011.xls (Dados CIS 2008). 